\title{
EDUCAÇÃO, TECNOLOGIAS DA INFORMAÇÃO E COMUNICAÇÃO: POSSIBILIDADES E DESAFIOS
}

Maria Salete Genovez | maria.genovez@aedu.com

Doutorado em Educação pela Universidade Estadual Paulista Júlio de Mesquita Filho

Nivaldo Carleto | nivaldo.carleto@aedu.com

Doutorado em Educação Escolar pela Universidade Estadual Paulista Júlio de Mesquita Filho.

Ana Maria Cardoso | ana.mcardoso@aedu.com

Doutorado em Literatura Brasileira pela Universidade Federal do Rio Grande do Sul.

Silvia Cristina M. Rodrigues | silvia.rodrigues1@aedu.com

Doutorado em Engenharia Elétrica pela Universidade de São Paulo.

\section{Resumo}

Com o aparecimento de inúmeras ferramentas tecnológicas, o uso das novas tecnologias da informação e da comunicação (NTIC) na gestão educacional e no ensino passou a ser considerado de fundamental importância. Por meio de pesquisa bibliográfica, procurou-se identificar e refletir sobre alguns aspectos que permeiam essa questão. O discurso comum é aquele que sugere que essas ferramentas vieram para resolver problemas operacionais, tanto nos aspectos administrativos quanto nos pedagógicos. Essa visão, um tanto reducionista, acaba fazendo das NTIC a solução eficaz para todas as dificuldades, desconsiderando outras questões mais amplas e profundas pelas quais passam os vários segmentos educacionais. É fundamental a implantação de políticas públicas, tanto nacionais quanto internacionais, para subsidiar e orientar as práticas de gestores e de professores para que as escolas encontrem a melhor forma de utilização das novas tecnologias, considerando-as como instrumentos tecnológicos que, por si sós, não provocarão mudanças no ensino e nem na sociedade.

\section{Palavras-chave}

Educação. Tecnologia da Informação. Comunicação. 


\section{Education, information and communication technologies: opportunities and challenges}

\section{Abstract}

With the emergence of numerous technological tools, the use of new technologies of information and communication (NTIC) in education management and teaching came to be considered of fundamental importance. Through a literature search, we sought to identify and reflect on some aspects that permeate this question. The common speech is one that suggests that these tools came to overcome managements craft both on the administrative aspects as the pedagogical aspects. This view, somewhat reductionist, just doing the NTIC the remedy for all ills educational, disregarding other issues broader and deeper through which they pass the various educational segments. It is essential to the implementation of public policies, both national and international support and guide the practice managers and teachers for schools to find the best way to use new technologies regarding them as technological tools that by themselves do not cause changes in education or in society.

\section{Keywords}

Education. Information technology.

Communication.

\section{Introdução}

A evolução da comunicação e da informação determinou progressos qualitativos importantes no desenvolvimento da própria sociedade e das próprias tecnologias da informação.

Informação e comunicação são conceitos distintos, porém complementares; não podem ser considerados sinônimos.

Etimologicamente, o termo "informação" advém do verbo informar, cunhado no século XV do latim "informare", que significava "dar forma, formar". [...] Dito de outro modo: a informação pode ser enviada e recebida, mas, para ir além disso, é preciso que se estabeleça um contrato entre emissor e receptor que implica codificação e decodificação, assim como produção de significado e atribuição de sentido por parte de ambos (MAMEDE-NEVES; DUARTE, 2008).

A invenção do papel permitiu o desenvolvimento da linguagem gráfica em ambos os aspectos, da palavra escrita e do desenho; o telefone, o fonógrafo e o rádio privilegiam a linguagem sonora, ou seja, a linguagem oral (falada) e a música; a fotografia, o cinema e a televisão facilitam a informação visual.

A passagem dos tipos de meios usados para informar e comunicar, ou seja, as modalidades de informação e comunicação falada, escrita e visual são absorvidas na atualidade por um único modo de efetivação, a eletrônica digital, que permite qualquer tipo ou forma de comunicação.

A popularização do uso do computador, aliada à rede mundial/internet, cada dia mais presente na vida das pessoas de todas as camadas sociais e de todas as faixas etárias, trouxe grandes e fortes mudanças em todas as áreas das atividades humanas. Com isso, novas e dinâmicas formas de acessar e processar informações surgem a cada dia.

O desenvolvimento da www (world wide web), junto com diversos outros bancos de dados públicos e comerciais on line, permitiu o acesso pessoal sem precedentes às informações mundiais mas apenas para as pessoas que possuem acesso físico às novas tecnologias e aos "letramentos informacionais" ${ }^{1}$ apropriados.

Todas as transformações técnicas, econômicas e culturais trouxeram como consequência, novas formas de conhecer, perceber e interpretar o mundo.

Desde muito cedo, principalmente a criança e o jovem já estão expostos a uma série de recursos tecnológicos decorrentes do desenvolvimento da informática e das telecomunicações.

1 Vide GASGUE, K.C.G.D. Arcabouço conceitual do letramento informacional. Ci. Inf., Brasilia, v. 39, n. 3, p. 83-92, set./dez., 2010. Disponível em: http://www.scielo.br/pdf/ci/v39n3/v39n3a07.pdf. Acesso em 18 dez.2013. 
O excesso/acúmulo de informações veiculadas pelos diferentes meios de comunicação e a velocidade com que elas são (re)transmitidas e difundidas acabam, muitas vezes, por dificultar o aprofundamento, a reflexão, a elaboração e a assimilação dessas informações para que se transformem em conhecimento.

Segundo Gouveia e Oliveira (2006, p. 23),

as tecnologias de inteligência $e$ as tecnologias de comunicação $e$ informação formam um complexo que permite a produção, o acesso, a circulação $e$ a veiculação das informações e de todas as demais formas de comunicação em e com diferentes partes do mundo.

Entre as habilidades e os entendimentos envolvidos na utilização das tecnologias da informação e comunicação (TIC) para localizar, avaliar e utilizar as informações inclui-se a capacidade de desenvolver boas perguntas de pesquisa; determinar os lugares mais prováveis onde procurar informações relevantes; selecionar a ferramenta de busca mais apropriada; formular questões de busca adequadas; avaliar rapidamente o resultado da questão de busca, incluindo a confiabilidade, a autoria e a aceitação geral da fonte; salvar e arquivar as informações localizadas; citar ou referir-se às informações localizadas (BUENO; SILVA, 2009).

Conclui-se que a grande alavanca para o surgimento de novas formas de sociedade, de relações sociais, de educação e de trabalho ocorreu com o surgimento e o desenvolvimento crescente das novas tecnologias.

Todo esse desenvolvimento tecnológico revolucionou a comunicação $e$ as formas de transmitir a informação; consequentemente, aplicando-se essas inovações à educação, mais especificamente ao ensino e à aprendizagem, vê-se claramente um avanço, embora não muito expressivo na forma de conduzir o processo educacional, tanto na relação entre aluno e professor quanto na relação ensinoaprendizagem.

\section{As NTIC na educação e no ensino}

Observa-se no cenário mundial que cada vez mais as NTIC fazem parte do dia a dia das pessoas. Elas estão presentes na maioria das ações de seu cotidiano: relações familiares, trabalho, educação, lazer/ entretenimento... A cada dia que passa surgem novas formas de relação interpessoal, relações com o mundo do trabalho e o mundo do saber. As NTIC tornaram-se necessárias para a sobrevivência no mundo de hoje, mas não são suficientes para garantir as transformações desejadas na escola e na sociedade que agora se apresenta com nova morfologia.

Pode-se considerar que a "sociedade em rede"2, considerada a nova morfologia social, é uma realidade no mundo atual. As redes sociais, por exemplo, permitem que os indivíduos participem de diferentes comunidades virtuais, tanto para troca quanto para apropriação de informações e novos conhecimentos.

No que concerne à justificativa conceitual sobre o assunto pesquisado, é possível verificar que as transformações sociais e educacionais proporcionadas pelas NTIC vêm promovendo possibilidades inovadoras na área educacional, não apenas no aspecto administrativo. No tocante à organização pedagógica, cada vez mais observa-se que a presença dessas tecnologias, quando bem utilizadas, pode introduzir mudanças significativas no cotidiano escolar.

Sabe-se que a educação escolar faz parte de uma estrutura hierarquizada; consequente e tradicionalmente fechada e restrita em tempos determinados (cronogramas, programas, calendário...) e a espaços físicos específicos (prédio escolar, sala de aula, biblioteca).

Com a aplicação das NTIC, essa estrutura começou a desestabilizar-se e a sofrer cobranças da própria sociedade para rever os conceitos tão enraizados de "ensinar e aprender". Apesar da resistência de muitos profissionais, a escola, os gestores e os professores estão

2 Vide CASTELLS, M. A sociedade em rede: do conhecimento à política. In: CASTELLS, M.; CARDOSO, G. A sociedade em rede: do conhecimento à acção política. Disponível em: http://biblio.ual.pt/Downloads/ REDE.pdf. Acesso em 28 out.13. 
sendo pressionados para que revejam sua função social, suas metodologias, seus procedimentos didáticos e suas formas de lidar com o conhecimento elaborado.

São atribuídos múltiplos sentidos ao uso das novas tecnologias de informação e comunicação na gestão educacional e no ensino. O mais comum é aquele que sugere que essas novas tecnologias vieram para agilizar situações operacionais, tanto nos aspectos administrativos quanto nos pedagógicos. Esse tipo de visão é um tanto reducionista, fazendo das NTIC o remédio para todos os problemas educacionais, desconsiderando outros aspectos mais amplos e mais profundos pelos quais passa a educação.

Evidentemente as inovações tecnológicas podem contribuir significativamente para a educação e a melhoria da relação ensino-aprendizagem.

Nos processos de ensino-aprendizagem, as NTIC podem ser consideradas estimuladoras e provocadoras de uma revolução na democratização do ensino, sobretudo na educação superior, porém essas inovações e esse aparato tecnológico ainda não trouxeram os resultados esperados.

Com foco na formação do indivíduo, nasceram novas propostas pedagógicas, educacionais e institucionais, com o objetivo de atender às novas demandas de formação no Ensino Superior. Dessa forma, inúmeros meios surgiram para atender à demanda dessa modalidade de ensino, contudo apenas a introdução da parafernália eletrônica como recurso didático-pedagógico não provocou as mudanças desejadas. Em muitos casos, ocorreu apenas a substituição do uso do quadro de giz pelo uso do aparelho multimídia. $\mathrm{Ou}$ seja, a metodologia e as práticas de ensino continuaram de forma tradicional.

Entende-se que, por si só, as NTIC não promovem mudanças nos processos de gestão e de ensino-aprendizagem, muito menos a propalada "transformação" da sociedade.

Para Barreto (2002),

a "aura de magia" que as envolve evidencia sua fetichização. Acredita-se em sua capacidade de desencadear mu- danças significativas no processo de ensino-aprendizagem, bem como de minimizar a lacuna entre as práticas escolares e as demais práticas sociais de docentes e discentes.

Moreira e Kramer (2007) afirmam que, sob essa ótica, as NTIC "deixam de ser entendidas como produções histórico-sociais, sendo vistas como fontes de transformações que consolidariam a sociedade da informação ou do conhecimento - expressão da qual estão ausentes os elementos sociopolíticos do 'novo' arranjo social". De acordo com esses autores, é importante observar "como a expressão se aplica, para que não termine homogeneizando movimentos heterogêneos ou grupos sociais excluídos das modalidades hegemônicas de conhecimento". A sociedade não deve ignorar as diferentes formas de diversidade cultural nela existentes, que jamais poderão ser suprimidas por meio de aparatos tecnológicos "avançados".

Ainda segundo os mesmos autores,

a expansão uniformizada de aparatos tecnológicos não elimina a diversidade das relações sociais entre indivíduos, assim como das relações desses indivíduos com o conhecimento, com o dinheiro e com seus corpos. Tampouco propicia desaparecimento de desigualdades econômicas. Assim, as diferenças, as desigualdades, as divergências e as discrepâncias persistem (MOREIRA; KRAMER, 2007).

Com o avanço tecnológico e o consequente advento de inúmeras ferramentas tecnológicas, a relação com o mundo exterior, os ambientes de trabalho, as formas de apropriação de informações e a construção do conhecimento também se transformaram.

\footnotetext{
Embora possa haver divergências quanto à qualidade e à quantidade dos resultados produzidos pelas novas tecnologias, existe uma unanimidade em reconhecer a inevitável responsabilidade do processo educativo em preparar ou, no mínimo, auxiliar o ser humano nos embates decorrentes dos novos desafios, procurando reduzir o gap entre o que é praticado e as necessidades emergentes dessa reconfiguração estrutural das relações do homem com seu meio ambiente (LIMA, 2000, p. 59).
} 
Todo esse universo que se descortina por meio desses recursos tecnológicos leva a criança $e$ o jovem a outros modos de contatar, perceber a situação e a realidade que os cercam e, consequentemente, conduzem-nos a outras formas de apropriação e construção da informação e do conhecimento; esse novo cenário exige, então das instituições de Educação Básica e de Educação Superior mudanças significativas nos modos como os professores lidam com a organização/transmissão do que se ensina $e$ do que se aprende.

A questão do uso das NTIC na Educação - principalmente na Educação Básica - envolve múltiplos aspectos que merecem uma análise mais apurada. São vários os entraves, tais como: a lentidão com que as escolas absorvem as transformações que ocorrem no mundo, o engessamento dos currículos escolares e a atuação dos professores.

Isso representa um grande e sério desafio para alunos, professores e gestores, que devem repensar metodologias, procedimentos didáticos, formas de gestão e principalmente as práticas pedagógicas para que estejam claramente estabelecidas em uma proposta pedagógica elaborada no projeto pedagógico de cada instituição.

\footnotetext{
Qualquer projeto pedagógico de um sistema a distância ou de um curso a distância, antes de delinear os aspectos operativos e organizacionais da ação educativa, deve explicitar seus fundamentos ontológicos (do que "é" ou expressos no "princípio da razão", para compreender a totalidade da realidade), mas sobretudo os epistemológicos (como se dá o processo de ensino e de aprendizagem?), axiológicos (para que, em que direção, com que valores?), históricos e políticos (em que contexto? Para quem? Que sociedade se quer construir?) (PRETI, s/d).
}

É evidente que os gestores escolares necessitam, cada vez mais, de sistemas capazes de administrar dados importantes na manutenção acadêmica, administrativa e financeira de uma unidade de ensino. Além disso, alunos e professores buscam a mediação tecnológica como suporte ao efetivo andamento do trabalho em sala de aula. Diante disso, laboratórios de informática, notebooks, tablets, netbooks, blogs, chats, grupos de discussão, e-books, redes sociais e ambientes virtuais de aprendizagem (AVA), por exemplo, passaram a fazer parte de uma nova realidade que, somada aos tradicionais meios de comunicação, incorporam uma nova ampliação da informação $e$ do conhecimento. Como consequência, esse novo cenário tem provocado nas instituições de ensino superior mudanças significativas nos modos como os alunos e os professores lidam com a organização do que se aprende e do que se ensina.

As possibilidades das NTIC na organização $e$ na administração de uma escola podem ser muitas: na gestão de pessoas, na gestão financeira, na gestão da aprendizagem - aqui incluindo a gestão do conhecimento. Na prática, pode-se observar sua utilização no âmbito acadêmico (serviços prestados aos alunos e professores): registro dos dados e das informações de forma sistêmica da vida escolar do aluno (formulário de matrícula, registro de notas e frequências), digitalização de documentos escolares (histórico escolar do aluno, declaração de matrícula, certificados de conclusão de curso e diplomas), informatização da biblioteca (empréstimos, devoluções e consulta ao acervo); observa-se também sua utilização no controle e na administração de recursos materiais e patrimoniais (controle de estoque, inventário de equipamentos de laboratório e aquisição de patrimônios), em reuniões de planejamento escolar, de conselho de classe e pedagógicas (para auxiliar os professores e coordenadores de curso a organizar as informações dos alunos por meio de gráficos, tabelas e relatórios, melhorando, dessa forma, as decisões tomadas coletivamente). Nessas condições, a proposta do uso das NTIC como ferramenta tecnológica para a articulação administrativa e pedagógica na gestão escolar proporciona a coleta, o armazenamento, o processamento e a recuperação de registros, podendo com isso viabilizar as ações educacionais, tendo em vista que o aluno é o ator principal no processo de ensino e aprendizagem. 
Nesse sentido, Almeida (2003), ressalta que

a incorporação das TIC vem se concretizando com maior frequência nas situações em que diretores e comunidade escolar se envolvem nas atividades como sujeitos do trabalho em realização, uma vez que o sucesso dessa incorporação está diretamente relacionado com a mobilização de todo o pessoal escolar, cujo apoio e compromisso para com as mudanças envolvidas nesse processo não se limitam ao âmbito estritamente pedagógico da sala de aula, mas se estendem aos diferentes aspectos envolvidos com a gestão do espaço e do tempo escolar, com a esfera administrativa e pedagógica. Daí a importância da formação de todos os profissionais que atuam na escola, fortalecendo o papel da direção na gestão das TIC e na busca de condições para o seu uso no ensino e aprendizagem, bem como na administração e na gestão escolar (ALMEIDA, 2003, p. 116).

Para Costas (2003), diretores, coordenadores e professores podem fazer da tecnologia uma ferramenta de apoio indispensável para o gerenciamento das atividades administrativas e pedagógicas. Com isso, estarão reduzindo a circulação de papéis, que se convertem em arquivos digitais e podem ser catalogados e organizados em pastas eletrônicas em um único computador central (um servidor, por exemplo) ou mesmo nos computadores distribuídos na escola (secretaria acadêmica e direção).

No âmbito pedagógico, pode-se dizer que é indiscutível a utilidade da tecnologia e dos aparatos tecnológicos, mas é importante que nesse processo sejam proporcionadas ao aluno condições para que acesse $e$ construa de forma autônoma o conhecimento.

A aprendizagem pode "transpor a distância temporal ou espacial" fazendo recursos às tecnologias "unidirecionais" (um a um, um e muitos), como o livro, o telefone ou a tecnologia digital, que é "multidirecional" (todos-todos) etc. eliminando a distância ou construindo interações diferentes daquelas presenciais. Mas, muito mais do que recorrendo à mediação tecnológica, é a relação humana, o encontro com o(s) outro(s) que possibilita ambiência de aprendizagem. Aprendizagem e educação são processos "presenciais", exigem o encontro, a troca, a co-operação, que podem ocorrer mesmo os sujeitos estando "a distância".

\begin{abstract}
"Presencialidade" pode significar, também, "estar juntos virtualmente". O espaço físico está dando lugar ao ciberespaço ou à construção de "redes de aprendizagem", em que professores e alunos aprendem juntos, interagem e cooperam entre si (PRETI, s/d).
\end{abstract}

A partir dessas reflexões, surgem algumas questões: de que forma utilizar as NTIC no sistema educacional de modo a torná-las ferramentas importantes e facilitadoras do processo educacional? Como relacionar o mundo do trabalho com as situações, os conteúdos, as metodologias de ensino e aprendizagem mediados por essas tecnologias? Como contextualizar práticas pedagógicas nesse universo em que os referenciais teóricos e operacionais estão em constante transformação?

Vive-se numa sociedade em que

as formas assumidas pela globalização mostram-se distintas, complexas e contraditórias. Assim, parece haver espaço para que, nas práticas pedagógicas, se escolham objetivos e procedimentos, oriundos "de baixo", dos grupos subalternizados, excluídos e marginalizados, que desestabilizem os processos hegemônicos. Pode também haver espaço para que se desafiem os modos usuais de prescrição de políticas e de promoção de mudanças nos sistemas educacionais. Pode, ainda, mostrar-se factível o redimensionamento da concepção vigente de qualidade na educação (MOREIRA; KRAMER, 2007).

Esses autores declaram que a educação de qualidade está diretamente relacionada às mudanças na escola, nos sistemas escolares e na sociedade. No caso da escola e dos sistemas escolares, as mudanças estão ligadas às condições de trabalho, conhecimentos, habilidades, procedimentos didáticos e de avaliação relevantes que favoreçam o ensino-aprendizagem; ao planejamento das atividades pedagógicas; às formas democráticas de gestão da escola, "colaboração de diferentes indivíduos e grupos; diálogo com experiências não formais de educação; além de docentes bem formados (que reconheçam o potencial do aluno e que concebam a educação como um direito e um bem social)". 
É importante salientar que, recentemente, o panorama educacional brasileiro foi alterado pela implantação de políticas públicas por parte do Ministério da Educação (MEC). As políticas adotadas em caráter nacional focalizaram a democratização, a expansão $e$ a interiorização da Educação Básica e da Educação Superior visando minimizar as desigualdades no acesso à informação ${ }^{3}$.

Com a parceria entre Governo Federal e demais entes federados, universidades e sociedade civil, essas políticas do MEC geraram ações voltadas à inclusão social de crianças, jovens e adultos que estiveram historicamente à margem dos sistemas educacionais. A Educação a Distância surge como um instrumento, fruto dos avanços tecnológicos, das NTIC aplicadas ao ensino, que apresenta inúmeros pontos positivos bem como pontos negativos.

Conforme afirma Santos (2012), "a EaD tem pontos muito fortes baseados na autonomia, autodidaxia, pesquisa e autoria, competências importantes na formação de um indivíduo crítico e consciente"; porém, como o contato pessoal com os alunos é muito menor ou nulo no ensino a distância, é muito difícil, por exemplo, o professor identificar individualmente os seus alunos ou observar essas mudanças comportamentais, critérios importantes para uma avaliação qualitativa. Entende-se que essa questão poderá ser resolvida ou minimizada por meio de um AVA bem elaborado e bem conduzido, com a adoção de práticas pedagógicas adequadas. Em contrapartida, também é possível observar que, numa sala de aula presencial com quarenta alunos ou mais, o contato pessoal poderá ser mínimo ou nulo...

Permeando e integrando os três eixos (democratização, expansão e interiorização da Educação Superior), observa-se que a EaD pode assumir um papel

3 C.f. Documentos legais promulgados e/ou textos divulgados pelo MEC, tais como: LDBEN - Lei $n^{\circ}$ 9.394, de 20 de dezembro de 1996; Decreto $n^{\circ}$ 6.094, de 24 de abril de 2007; PDE (Plano Nacional de Desenvolvimento da Educação), de 24 de abril de 2007, lançado concomitantemente com o Decreto $n^{\circ}$ 6.094/07; Emenda Constitucional $n^{\circ}$ 59, de 2009; PNE (Plano Nacional de Educação) - Projeto de Lei no 8.035-B, de 2010 (redação final), para vigorar de 2011 a 2020, trazem essas características. de destaque principalmente no tocante à democratização do acesso à Educação Superior, de modo especial para aqueles indivíduos que residem em locais geograficamente distantes dos polos educacionais.

Para Werthein (2000, p. 77),

será essencial identificar o papel que essas novas tecnologias podem desempenhar no processo de desenvolvimento educacional e, isso posto, resolver como utilizá-las de forma a facilitar uma efetiva aceleração do processo em direção à educação para todos, ao longo da vida, com qualidade e garantia de diversidade.

Com o objetivo de diminuir as dificuldades $e$ defasagens históricas do acesso aos bens culturais que remontam décadas e décadas, as várias instâncias governamentais estabeleceram programas que incluíram/ incluem aquisição de computadores, softwares, instalação de "banda larga" na maioria de suas escolas, além de recursos financeiros para aquisição de equipamentos tecnológicos como forma de responder aos desafios impostos pela atual sociedade e assim facilitar o acesso à informação e ao conhecimento elaborado.

\section{Considerações finais}

As transformações pelas quais passa a sociedade impulsionam novas formas de acesso, construção $e$ socialização do conhecimento, novas formas de produção e de relações humanas, econômicas, políticas, culturais e sociais. Essas mudanças acabam exigindo que o sistema escolar se adapte às novas exigências do mercado e forme pessoas com "novos" conhecimentos, "novas" competências e habilidades. Diante desse quadro, a escola não pode ignorar esse contexto e agir de forma isolada. Ela deve, por meio de currículos centrados na formação contínua de seus alunos, colocar-se a serviço da promoção humana, formando sujeitos críticos, cidadãos atuantes e reflexivos que estejam preparados para viver e conviver numa sociedade em constante mudança. Ao utilizar ferramentas tecnológicas disponíveis para cumprir sua função 
social, estabelecendo-se como espaço de luta contra a exclusão social, a escola estará contribuindo para a construção da democracia.

É importante registrar que a simples aquisição de equipamentos como computadores, notebooks para alunos, laboratórios de informática e outros aparatos tecnológicos não garante o sucesso do processo educacional e os resultados eficazes desejados.

Entre outras preocupações, destaca-se a necessidade de atualização dos profissionais de educação quanto às competências necessárias para o uso dessas ferramentas que apresentam novas funções para atender às novas exigências da atual sociedade.

Há que se considerar que a simples "instrumentalização" do professor para utilização dos equipamentos não é suficiente. Ela deve estar aliada a um processo contínuo de reflexão, orientação e acompanhamento técnico-pedagógico desses profissionais por meio de uma equipe multidisciplinar para o devido suporte técnico, manutenção dos equipamentos e para auxiliar os professores na mediação/integração do aparato tecnológico à sua metodologia e conteúdo programático. Além disso, é fundamental que haja uma visão crítica sobre o processo educacional: fins e objetivos. Ou seja: que tipo de pessoa a escola quer formar? Em que sociedade ela está inserida? Que ferramentas serão necessárias para que ela possa viver e conviver com dignidade? De que maneira as NTIC poderão contribuir para facilitar o acesso aos bens culturais e contribuir para a formação do cidadão crítico?

Cumpre salientar também que é necessário que haja a adoção e a implementação de políticas públicas pelos entes federados que levem - democraticamente - crianças, jovens e adultos à apropriação das ferramentas tecnológicas, de modo reflexivo, para poderem acessar, receber, socializar, compartilhar informações e possam, por meio desse "passaporte", ingressar e se estabelecer na "sociedade da informação".

É interessante registrar também um possível paradoxo: a mediação tecnológica entre ensino e aprendizagem, aluno e professor permite que haja mais liberdade entre docentes e discentes para serem os sujeitos desse processo; porém, por conta do distanciamento entre ambos (gerado pelo mesmo aparato tecnológico), pode ocorrer a banalização das relações interpessoais e sociais que pode ter como causa o mau uso dessa mesma tecnologia.

A utilização das NTIC no terreno educacional terá cumprido sua verdadeira função quando houver clareza de que o importante não é a tecnologia em si mesma; é essencial que haja a adoção de uma pedagogia dialógica, interativa, que sustente e garanta a relação entre pessoas (gestores, professores, alunos) $e$ conhecimento elaborado e que sejam mediados pela realidade que os cerca. Isso supõe cooperação, diálogo, participação, interação e reflexão entre as partes. Juntamente com a eliminação das distâncias, aparecem novas relações de tempo e espaço, e com elas surgem novas exigências. Isso gera novos e constantes desafios. A questão é muito séria e complexa, envolvendo aspectos educacionais, econômicos, políticos e sociais que tanto podem facilitar quanto dificultar a compreensão da temática.

\section{Referências}

ALMEIDA, M. E. B. Tecnologias e gestão do conhecimento na escola. In: VIEIRA, Alexandre Thomaz; ALMEIDA, Maria Elizabeth Bianconcini; ALONSO, Myrtes (org.). Gestão educacional e tecnologia. São Paulo: Avercamp, 2003.

BARBOSA, E. F; MOURA, D. G. de; BARBOSA, A. F. Inclusão das tecnologias de informação e comunicação na educação através de projetos. Disponível em: http://www.tecnologiadeprojetos.com.br/ banco_objetos/\%7BC36C8E12-B78C-4FFB-AB60-C428F2EB. Acesso em 21 ago.2013.

BARRETO, R. G. Tecnologias nas salas de aula. In: LEITE, M.; URANI, A.; FILÉ, V. 
Subjetividades, tecnologias e escolas. Rio de Janeiro: DP\&A, 2002.

BUENO, Douglas A.; SILVA, Simone C. P. Cidadania e integração social da tecnologia: Fragmentos para uma Reflexão Crítica. IV Congresso da Cibersociedade. Crise Analógica, futuro digital. Espanha: Observatorio para la Cibersociedad, 2009.

COSTAS, J. M. M. Gestão inovadora com tecnologias. In: VIEIRA, Alexandre Thomaz; ALMEIDA, Maria Elizabeth Bianconcini; ALONSO, Myrtes (org.). Gestão educacional e tecnologia. São Paulo: Avercamp, 2003.

GOUVEAA, G.; OLIVEIRA, C. I. de C. Educação a distância na formação de professores: viabilidade, potencialidades e limites. Rio de Janeiro: Vieira e Lent, 2006.

LIMA, F. O. A sociedade digital: impacto da tecnologia na sociedade, na cultura, na educação e nas organizações. Rio de Janeiro: Qualitymark, 2000.

MAMEDE-NEVES, M. A. C.; DUARTE, R. O contexto dos novos recursos tecnológicos de informação e comunicação e a escola. Educação e Sociedade, Campinas, v. 29, n. 104 - Especial, p. 769-789, out. 2008. Disponível em http://www.cedes.unicamp.br. Acesso em 21 ago. 2013.

MOREIRA, Antonio Flavio Barbosa; KRAMER, Sonia. Contemporaneidade, educação e tecnologia. Educação e Sociedade, Campinas, v. 28, n. 100 - Especial, p. 1.037-1.057, out. 2007. Disponível em http://www.cedes. unicamp.br. Acesso em 18 jul. 2012.

PRETI, O. Bases epistemológicas e teorias em construção na educação a distância. Disponível em: http://www.uab.ufmt.br/uab/images/artigos_site_uab/bases_epistemologicas.pdf. Acesso em 09 out. 2013.

SANTOS, João Francisco Severo. A avaliação no ensino a distância. Revista Iberoamericana de Educación, v. 58, jan./abr. 2012.

SARTORI, A. S. Inter-relações educação-comunicação na educação superior. Disponível em: http:// www.abed.org.br/congresso2005/por/pdf/196tcc3.pdf. Acesso em 29 ago. 2013.

WERTHEIN, J. A sociedade da informação e seus desafios. Disponível em:

http://www.scielo.br/pdf/ci/v29n2/a09v29n2.pdf. Acesso em 10 set. 2013. 